\title{
Identification of the Stress Which Causes Optineurin Aggregation
}

\author{
Satoshi Inagaki 1,2, Michinori Funato², Junko Seki², Chizuru Kawase², \\ Kazuki Ohuchi1,2, Shiori Ando1,2, Shinsuke Nakamura1, \\ Masamitsu Shimazawa ${ }^{1}$, Hideo Kaneko² ${ }^{2}$, Hideaki Hara1 \\ ${ }^{1}$ Molecular Pharmacology, Department of Biofunctional Evaluation, Gifu Pharmaceutical University, Gifu, Japan \\ ${ }^{2}$ Department of Clinical Research, National Hospital Organization, Nagara Medical Center, Gifu, Japan \\ Email: *shimazawa@gifu-pu.ac.jp
}

How to cite this paper: Inagaki, S., Funato, M., Seki, J., Kawase, C., Ohuchi, K., Ando, S., Nakamura, S., Shimazawa, M., Kaneko, H. and Hara, H. (2019) Identification of the Stress Which Causes Optineurin Aggregation. Neuroscience \& Medicine, 10, 150-161.

https://doi.org/10.4236/nm.2019.102010

Received: March 28, 2019

Accepted: June 7, 2019

Published: June 10, 2019

Copyright $\odot 2019$ by author(s) and Scientific Research Publishing Inc. This work is licensed under the Creative Commons Attribution International License (CC BY 4.0).

http://creativecommons.org/licenses/by/4.0/

(c) (i) Open Access

\begin{abstract}
Glaucoma is a common neurodegenerative disease that can cause blindness and occurs worldwide. Currently, lowering intraocular pressure is the only therapy available to protect retinal ganglion cells (RGCs). However, this therapy does not prevent RGC death in all patients. Therefore, new therapeutic approaches for glaucoma are urgently required, and neuroprotection of RGCs is a focus for many researchers. Optineurin (OPTN) is one of the normal tension glaucoma (NTG) relative genes, while mutant OPTN can form a characteristic aggregation, causing RGC death. Hence, elucidation of the mechanism of OPTN aggregation might provide a clue to help understand RGC death. To examine whether non-mutant OPTN could also aggregate, we pharmacologically induced some glaucoma-related stresses, such as endoplasmic reticulum (ER) stress, glutamate toxicity, activation of TNF- $\alpha$ signaling, mitochondrial dysfunction, and autophagic flux impairment. Our results showed that ER stress, TNF- $\alpha$ signaling, and autophagic flux are involved in OPTN aggregation. Furthermore, our data indicated that increased ER stress, activation of TNF- $\alpha$ signaling, and impaired autophagic flux induce OPTN aggregation, suggesting that OPTN aggregation might be an important therapeutic target not only for familial NTG with mutated OPTN but also for patients with glaucoma more generally.
\end{abstract}

\section{Keywords}

Glaucoma, Induced Pluripotent Stem Cells, Retinal Ganglion Cells, Optineurin, Protein Aggregation 


\section{Introduction}

Glaucoma is characterized by the progressive loss of retinal ganglion cells (RGCs) and their axons, and is one of the leading causes of irreversible blindness worldwide [1]. Primary open-angle glaucoma (POAG) is the most common type of glaucoma. POAG is classified into two subsets: high tension glaucoma (HTG) and normal tension glaucoma (NTG). The only therapy currently available for POAG is the lowering of intraocular pressure (IOP). However, some individuals develop glaucoma when their IOP is in the normal range [2] [3]. In addition, NTG is the major subtype that occurs in patients with glaucoma in Japan [4]. It has been suggested that glaucoma is caused not only by high IOP but also by other, unknown risk factors in its pathology [5].

In research undertaken to discover the complex mechanisms of glaucoma pathology, genetic and genomic studies have accelerated the discovery of genes that contribute to glaucoma. It is reported that optineurin (OPTN) gene mutations, such as E50K $\left(\mathrm{OPTN}^{\mathrm{E50K}}\right)$ and M98K $\left(\mathrm{OPTN}^{\mathrm{M} 98 \mathrm{~K}}\right)$, are associated with NTG, and that patients with these mutations exhibited severe glaucoma symptoms [6]-[11]. The OPTN protein plays multiple roles in various processes, such as autophagic flux [12] [13], where it is an important regulator, and NF- $\kappa B$ signaling [14] [15]. However, it has been reported that both $\mathrm{OPTN}^{\mathrm{E} 50 \mathrm{~K}}$ and $\mathrm{OPTN}^{\mathrm{M} 98 \mathrm{~K}}$ mutations result in protein aggregation [16] [17], and that $\mathrm{OPTN}^{\mathrm{E} 50 \mathrm{~K}}$ interacts more strongly with TBK1 and causes autophagic flux dysregulation, leading to RGC degeneration [17] [18] [19] [20] [21]. Hence, we explored the use of chemical agents to reduce OPTN aggregation, and found that timolol has the potential to decrease OPTN aggregation and shows neuroprotective effects in familial NTG patients with $\mathrm{OPTN}^{\mathrm{E50K}}$ iPSC-derived RGCs (E50K-iPSCs-RGCs) [20]. This work demonstrated that OPTN aggregation, which is the common phenotype among $\mathrm{OPTN}^{\mathrm{E} 50 \mathrm{~K}}$ and $\mathrm{OPTN}^{\mathrm{M} 98 \mathrm{~K}}$, might be an important pathology and a potentially useful therapeutic target in cases of familial glaucoma caused by OPTN mutation.

Hence, we examined whether OPTN aggregation might result not only from OPTN mutation but also following stress associated with RGC death in some glaucoma pathologies.

\section{Materials and Methods}

\subsection{Ethical Considerations}

The research followed the tenets of the Declaration of Helsinki. Informed consent was obtained from all participants after explaining to them the nature and possible consequences of the study. The procedures used for the pathological analyses and establishment of patient-derived iPSCs, including human gene analyses, were approved by the Ethics Review Committee of the National Hospital Organization, Nagara Medical Center, Gifu University and Gifu Pharmaceutical University, Japan. The established human iPSCs were handled according to the Revisions of the Guidelines for Clinical Research using Human Stem Cell from the Ministry of Health, Labor, and Welfare of Japan. 


\subsection{Differentiation of Induced Pluripotent Stem Cells (iPSCs) into Retinal Ganglion Cells (RGCs) in Culture}

In this study, we used the 201B7 iPSC line. This line was provided by Kyoto University [22]. The culture of isolated iPSCs and the production of embryoid bodies using the quick reaggregation (SFEBq) method was performed as previously described [22] [23] [24]. To create mimics of normal RGCs, we used a previously described, modified protocol [20] [25]. Briefly, the day after the culture was started, the culture medium was changed to a differentiation medium consisting of Dulbecco's Modified Eagle Medium/F12 (Invitrogen), 1\% N2 supplement (Invitrogen), B27 supplement, L-glutamine, $500 \mathrm{U} / \mathrm{ml}$ penicillin/streptomycin (Invitrogen), $2 \mu \mathrm{M}$ dorsomorphin (Sigma-Aldrich), $10 \mathrm{ng} / \mathrm{ml}$ human Dickkopf 1 (R \& D Systems, Minneapolis, USA), $10 \mathrm{ng} / \mathrm{ml}$ insulin-like growth factor-1 ( $\mathrm{R} \& \mathrm{D}$ Systems), and $10 \mathrm{ng} / \mathrm{ml}$ bFGF (R \& D Systems), and cultured for 7 days in $5 \% \mathrm{CO}_{2}$ at $37^{\circ} \mathrm{C}$. Neuronal precursor cells were cultured in differentiation medium containing $10 \mu \mathrm{M} \mathrm{N}$-[(3][5-Difluorophenyl)acetyl]-L-alanyl-2-phenylglycine-1,1-dimethyl ester (DAPT; Tocris Bioscience, Avonmouth, UK) for a further 7 days to retinal ganglion cell lineage as previous report [26]. For the final stage, the neuronal precursor cells were cultured with the addition of $2 \mathrm{ng} / \mathrm{ml}$ acidic fibroblast growth factor ( $\mathrm{R} \& \mathrm{D}$ Systems) to the differentiation medium for 11 days. The medium was changed every 2 or 3 days for all differentiation stages. Finally, all cells except the embryoid bodies were reseeded onto Matrigel-coated plates.

\subsection{Western Blot Analyses}

At the end of the culture period, samples were washed with PBS and lysed in radioimmunoprecipitation assay (RIPA) buffer containing $50 \mathrm{mM}$ tris hydrochloride, $150 \mathrm{mM}$ sodium chloride, $0.5 \%$ sodium deoxycholate, $0.1 \%$ sodium dodecyl sulfate (SDS), 1\% Igepal CA-630, and protease (Sigma-Aldrich) and phosphatase inhibitor (Sigma-Aldrich) cocktails. The lysates were centrifuged at 12,000 $\mathrm{g}$ for $10 \mathrm{~min}$ at $4^{\circ} \mathrm{C}$. The protein concentration was determined using a bicinchoninic acid assay protein assay kit (Pierce Biotechnology, Rockford, IL, USA) with bovine serum albumin as the standard. Equal volumes of the lysate and sample buffer containing 20\% 2-mercaptoethanol (Wako) were mixed, and the proteins were separated using 5\% - 20\% SDS-polyacrylamide-gel electrophoresis (Wako). The separated proteins were then transferred onto a polyvinylidene difluoride

Table 1. Antibodies: All antibodies for the biochemical analysis were purchased from the following companies and used at the following dilutions.

\begin{tabular}{ccc}
\hline Antibody & Source & Dilution \\
\hline anti-OPTN & Cayman & $1: 200$ \\
anti-TBK1 & Cell Signaling Technology & $1: 1000$ \\
anti- $\beta$-actin & Sigma Aldrich & $1: 2000$ \\
anti-LC3B & Cell Signaling Technology & $1: 1000$ \\
Anti-p62 & Cell Signaling Technology & $1: 1000$ \\
\hline
\end{tabular}


membrane (PVDF, Immobilon-P; Merck KGaA, Darmstadt, Germany). The immunoreactive bands were made visible using ImmunoStar ${ }^{\circledR} \mathrm{LD}$, and the intensities of the bands were determined by ImageQuant LAS 4000. For the OPTN aggregation assay, we followed a previously reported protocol [17]. Briefly, we lysed cells using TNE buffer and centrifuged the lysates at 15,000 $\mathrm{g}$ for $15 \mathrm{~min}$. Then, we separated the supernatant and precipitated the insoluble pellet fraction (TNE insoluble fraction), and equal volumes of the lysate were used for the assay. Finally, we used appropriate antibodies (Table 1).

\subsection{Evaluation of Various Compounds That Induce Stress in WT-iPSCs-RGCs}

All compounds tested were purchased from the companies and used at the dilutions shown (Table 2). In this assay, the vehicle group contained $0.1 \%$ DMSO. We treated WT-iPSCs-RGCs with each chemical or protein for $24 \mathrm{~h}$.

\subsection{Statistical Analyses}

Data are presented as means \pm standard error of the means (SEMs). Unpaired Student's $t$-tests were used to determine if there were significant differences between two samples. ANOVA, followed by Dunnett's test or the Bonferroni test, was used to compare means in multigroup analyses. The level of statistical significance was set at $P<0.05$.

\section{Results}

Identification of Stresses That Induce OPTN Aggregation

To evaluate whether OPTN might aggregate in WT-iPSCs-RGCs following the induction of pharmacological stresses related to RGC degeneration, we evaluated OPTN protein levels in the TNE buffer insoluble fraction, as previously described [17]. RGC death in patients with glaucoma or experimental animal models is related to elevated endoplasmic reticulum (ER) stress [27] [28] [29], increased excitatory glutamate [30] [31], TNF- $\alpha$ signaling [32] [33] [34] [35], oxidative stress [36], mitochondrial dysfunction [21] [36] [37], and abnormal autophagic flux [38] [39] [40]. Based on this knowledge, we treated WT-iPSCs-RGCs with one of six compounds (Table 2) for 24 hours to explore if any of the agents

Table 2. Compounds that induce stress in WT-iPSCs-RGCs.

\begin{tabular}{ccc}
\hline Compound & Source & Dilution \\
\hline Tunicamycin & FUJIFILM Wako & $2 \mu \mathrm{g} / \mathrm{ml}$ \\
Glutamate & FUJIFILM Wako & $200 \mu \mathrm{M}$ \\
TNF- $\alpha$ & Merck KGaA & $12.5 \mathrm{ng} / \mathrm{ml}$ \\
Rotenone & FUJIFILM Wako & $0.1 \mu \mathrm{M}$ \\
$\mathrm{H}_{2} \mathrm{O}_{2}$ & FUJIFILM Wako & $100 \mu \mathrm{M}$ \\
Bafilomycin & Tocris Bioscience & $100 \mathrm{ng} / \mathrm{ml}$ \\
\hline
\end{tabular}


induced OPTN aggregation. In this assay, we evaluated tunicamycin (an ER stress inducer), glutamate, tumor necrosis factor $\alpha$ (TNF- $\alpha$ ), rotenone (a mitochondrial dysfunction inducer), $\mathrm{H}_{2} \mathrm{O}_{2}$, and bafilomycin (an autophagolysosome inhibitor). Our previous study demonstrated that bafilomycin induces OPTN aggregation [20], therefore we used it as a positive control. Their concentration is determined as inducing about $20 \%$ - 30\% of cell death [29] [41] [42] [43] [44]. Tunicamycin, TNF- $\alpha$, and bafilomycin increased OPTN aggregation in WT-iPSCs-RGCs (Figure 1(a) and Figure 1(b)), suggesting that OPTN aggregation occurs following ER stress, impairment of autophagolysosomes, and in the presence of TNF- $\alpha$.

Identification of the Mechanism Involved in OPTN Aggregation

To investigate the mechanism underlying OPTN aggregation, we first evaluated autophagic flux and TBK1 expression, because OPTN ${ }^{\mathrm{E} 50 \mathrm{~K}}$ impairs autophagolysosome and interacts strongly with TBK1, leading to aggregation of OPTN [45]. We found that bafilomycin increased the ratio of LC3B-II/LC3B-I (autophagosome markers, Figure 2(a) and Figure 2(b)) and the expression of p62 (an autophagolysosome marker, Figure 2(a) and Figure 2(c)), suggesting that bafilomycin impaired autophagic flux, leading to OPTN aggregation (Figure 4). However, tunicamycin and TNF- $\alpha$ had no influence on the LC3B-II/LC3B-I ratio or p62

(a)
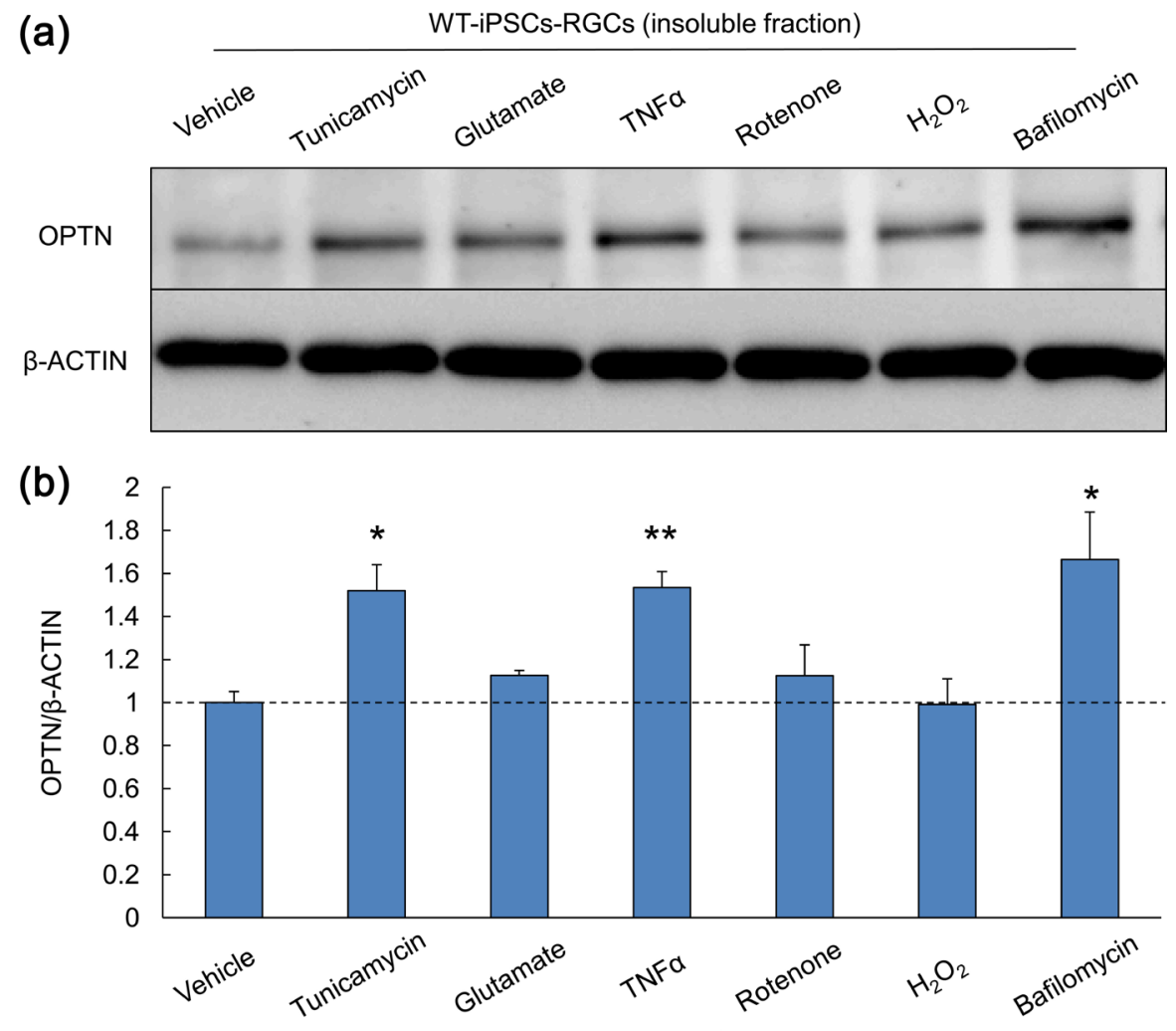

WT-iPSCs-RGCs (insoluble fraction)

Figure 1. Identification of the stress of OPTN aggregation in WT-iPSCs-RGCs. (a) Typical images showing western blotting analysis of TNE-buffer insoluble (aggregated) OPTN protein levels; (b) Quantitative data showing OPTN protein levels. Data are means \pm SEMs, $\mathrm{n}=7\left({ }^{\star \star} P<0.01,{ }^{\star} P<0.05\right.$ vs. vehicle, Student's $t$-test $)$. 

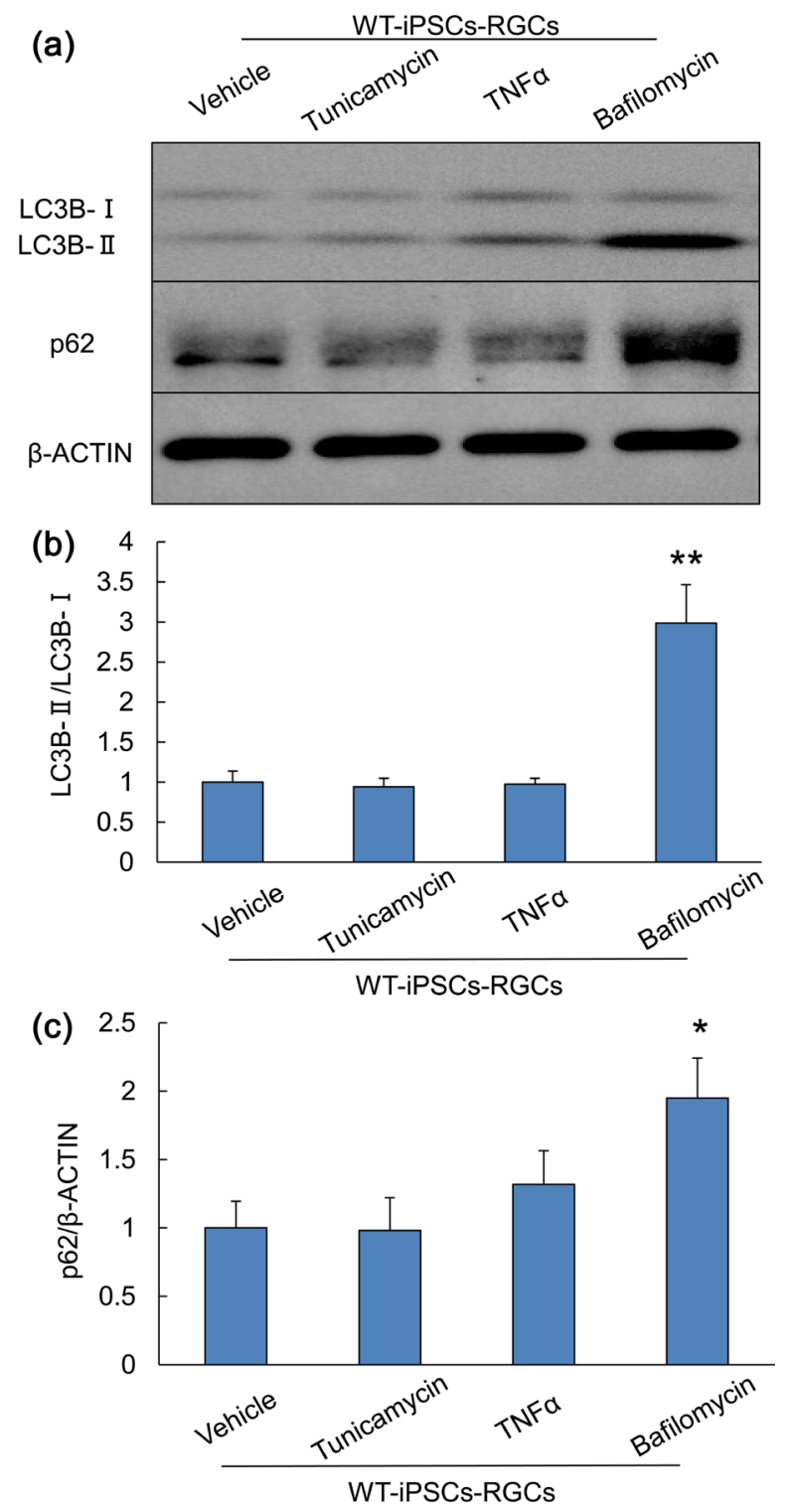

Figure 2. Autophagic flux assay with tunicamycin, TNF $\alpha$, and bafilomycin. (a) Typical images showing western blotting analysis of LC3B-II, LC3B-I, and p62 protein levels; (b) Quantification of protein expression of LC3B-II, LC3B-I ratio, and p62. Data are means \pm SEMs, $\mathrm{n}=7\left({ }^{*} P<0.01,{ }^{\star} P<0.05\right.$ vs. vehicle, Student's $t$-test $)$.

expression, suggesting that they had no influence on autophagic flux in this assay (Figures 2(a)-(c)). Therefore, we next evaluated the influence of stress on TBK1 expression (Figure 3). Although tunicamycin and bafilomycin had no effect on TBK1 expression, TNF- $\alpha$ had the potential to increase TBK1 expression (Figure 3(a) and Figure 3(b)), suggesting that TNF- $\alpha$ increased TBK1 expression, leading to OPTN aggregation (Figure 4).

\section{Discussion}

A previous study found that $\mathrm{OPTN}^{\mathrm{E} 50 \mathrm{~K}}$, a mutated form of OPTN, aggregates, and that this aggregation might cause the death of RGCs [45]. In this study, we 

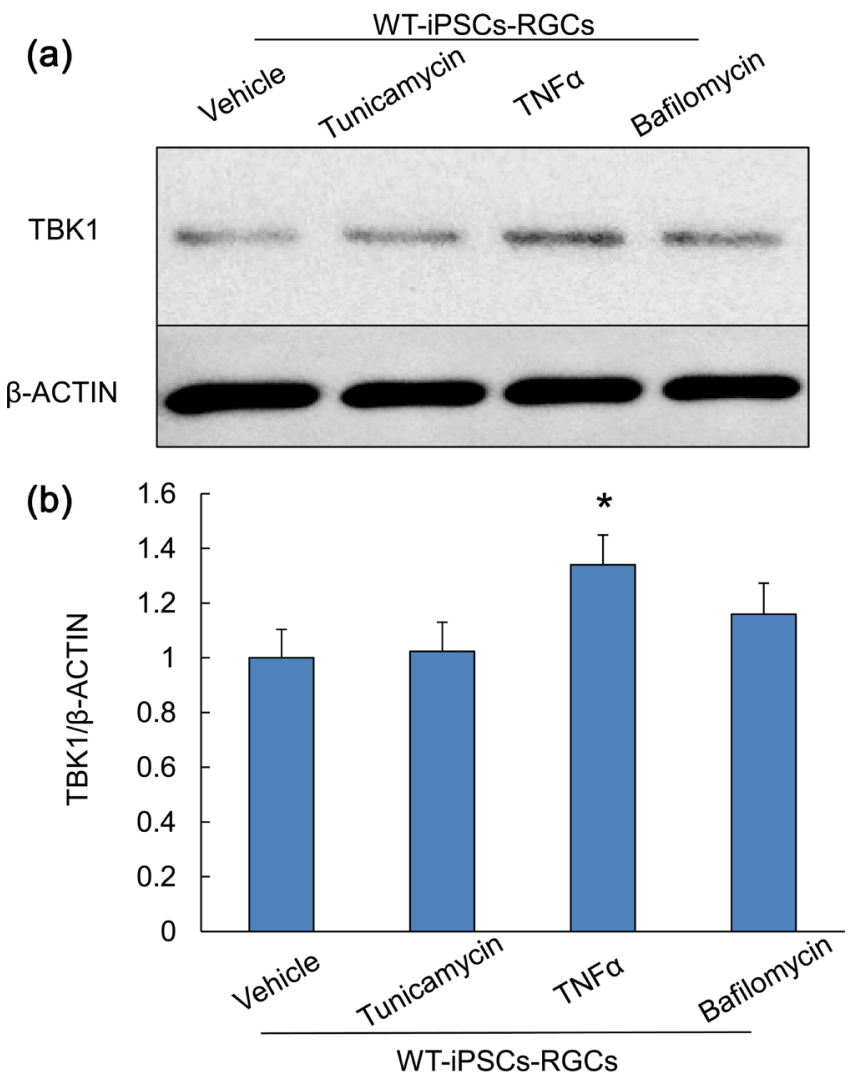

Figure 3. TBK1 protein assay with tunicamycin, TNF $\alpha$, and bafilomycin. (a) Typical images showing western blotting analysis of TBK1 protein levels; (b) Quantification of protein expression of TBK1. Data are means \pm SEMs, $n=7\left({ }^{*} P<0.05\right.$ vs. vehicle, Student's $t$-test).

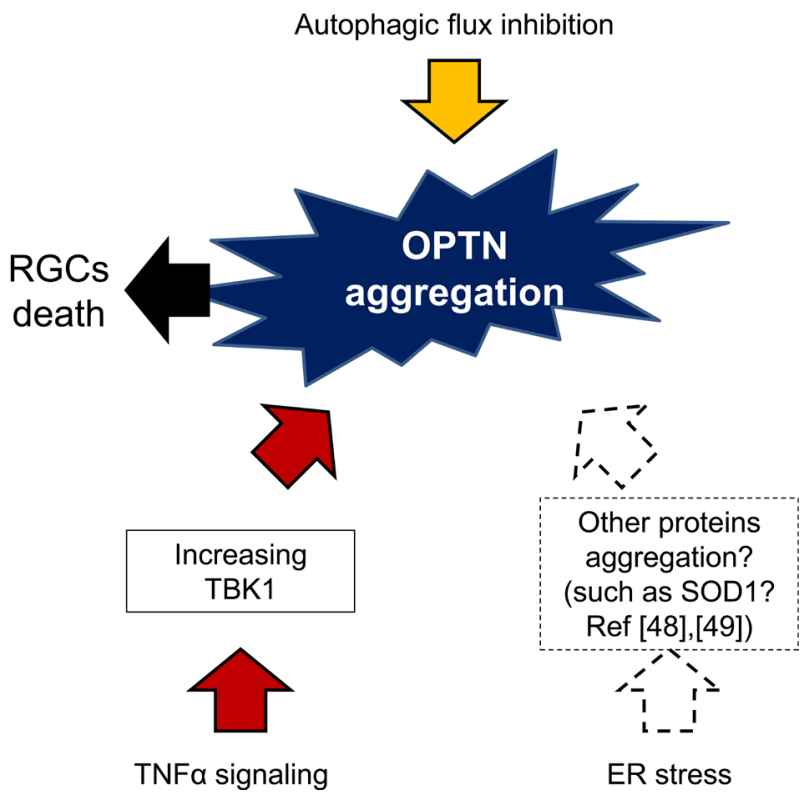

Figure 4. The scheme of OPTN aggregation formation. OPTN aggregation was produced by tunicamycin-induced ER stress, TNF $\alpha$-induced increased TBK1 expression, and bafilomycin-induced autophagic flux impairment. In this figure, the arrows showing broken line means speculation based on the previous reports Ref. [48] and [49]. 
demonstrated that $\mathrm{OPTN}^{\mathrm{WT}}$ aggregation was also caused by ER stress, TNF $\alpha$ signaling activation, and autophagy dysfunction. Considering that these stresses have been linked with glaucoma pathology, in both patients and experimental models, we suggest that OPTN aggregation might occur in RGCs without OPTN mutation. This could be a very important finding, as it implies that OPTN aggregation might possibly be involved not only in patients with familial glaucoma with OPTN but also patients with glaucoma who lack OPTN ${ }^{\mathrm{E} 50 \mathrm{~K}}$. Based on this, it is important to elucidate the mechanism by which OPTN aggregates. Our previous study suggested that promoting autophagic flux decreased OPTN aggregation [20]. Thus, the promotion of autophagic flux could be a therapeutic target. TNF $\alpha$ also stimulated OPTN aggregation by increasing the expression of TBK1. A previous report suggested that TBK1 is present downstream of the TNF $\alpha$ receptor [46]. Thus, attenuation of TNF $\alpha$ signaling-induced increases in TBK1 expression might also be a therapeutic target to prevent OPTN aggregation. We were unable to identify the mechanism behind tunicamycin-induced OPTN aggregation because autophagic flux and TBK1 expression did not change. Tunicamycin induces ER stress via the inhibition of protein glycosylation. However, it has been reported that OPTN is not glycosylated [47]. Hence, tunicamycin might not directly influence OPTN conformation. Tunicamycin is also known to induce protein aggregation of SOD1 without its mutation [48]. In addition, OPTN has the potential to bind aggregated proteins such as mutant SOD1 and huntingtin, and OPTN deficiency accelerates the aggregation of these proteins [49]. Therefore, when tunicamycin treatment produces aggregated proteins, such as SOD1 and huntingtin, OPTN might interact with these proteins, causing their aggregation (Figure 4). However, further studies are needed to demonstrate this hypothesis.

Our study demonstrated that glaucoma-related stresses can lead to aggregation of non-mutated OPTN. This knowledge might be important to elucidate novel pathologies of glaucoma.

\section{Acknowledgements}

The authors thank the patient who participated in this study and her families. We also thank Dr. K. Osafune (Kyoto University) for providing the human iPSC line 201B7.

\section{Conflicts of Interest}

The authors declare that they have no conflicts of interest.

\section{Author Contributions}

SI, MS, and HH designed the experiments. SI, JS, CK, KO, SA, performed the experiments. MF, SN, MS, HK, and HH supervised the study. SI wrote the manuscript. All authors discussed the results and commented on the manuscript. 


\section{References}

[1] Flaxman, S.R., Bourne, R.R.A., Resnikoff, S., Ackland, P., Braithwaite, T., Cicinelli, M.V., Das, A., Jonas, J.B., et al. (2017) Global Causes of Blindness and Distance Vision Impairment 1990-2020: A Systematic Review and Meta-Analysis. The Lancet Global Health, 5, e1221-e1234.

[2] Kass, M.A., Heuer, D.K., Higginbotham, E.J., Johnson, C.A., Keltner, J.L., Miller, J.P., Parrish, R.K., et al. (2002) The Ocular Hypertension Treatment Study: A Randomized Trial Determines that Topical Ocular Hypotensive Medication Delays or Prevents the Onset of Primary Open-Angle Glaucoma. Archives of Ophthalmology, 120, 701-713. https://doi.org/10.1001/archopht.120.6.701

[3] Collaborative Normal-Tension Glaucoma Study Group (1998) The Effectiveness of Intraocular Pressure Reduction in the Treatment of Normal-Tension Glaucoma. American Journal of Ophthalmology, 126, 498-505. https://doi.org/10.1016/S0002-9394(98)00272-4

[4] Iwase, A., Suzuki, Y., Araie, M., Yamamoto, T., Abe, H., Shirato, S., Kuwayama, Y., Mishima, H.K., Shimizu, H., Tomita, G., Inoue, Y. and Kitazawa, Y. (2004) The Prevalence of Primary Open-Angle Glaucoma in Japanese: The Tajimi Study. Ophthalmology, 111, 1641-1648. https://doi.org/10.1016/j.ophtha.2004.03.029

[5] Naito, T., Fujiwara, M., Miki, T., Araki, R., Fujiwara, A., Shiode, Y., Morizane, Y., Nagayama, M. and Shiraga, F. (2017) Effect of Trabeculectomy on Visual Field Progression in Japanese Progressive Normal-Tension Glaucoma with Intraocular Pressure <15 mmHg. PLoS ONE, 12, e0184096.

https://doi.org/10.1371/journal.pone.0184096

[6] Rezaie, T., Child, A., Hitchings, R., Brice, G., Miller, L., Coca-Prados, M., Heon, E., Krupin, T., Ritch, R., Kreutzer, D., Crick, R.P. and Sarfarazi, M. (2002) Adult-Onset Primary Open-Angle Glaucoma Caused by Mutations in Optineurin. Science, 295, 1077-1079. https://doi.org/10.1126/science.1066901

[7] Aung, T., Rezaie, T., Okada, K., Viswanathan, A.C., Child, A.H., Brice, G., et al. (2005) Hitchings, Clinical Features and Course of Patients with Glaucoma with the E50K Mutation in the Optineurin Gene. Investigative Ophthalmology \& Visual Science, 46, 2816-2822. https://doi.org/10.1167/iovs.04-1133

[8] Tham, Y.C., Li, X., Wong, T.Y., Quigley, H.A., Aung, T. and Cheng, C.Y. (2014) Global Prevalence of Glaucoma and Projections of Glaucoma Burden through 2040: A Systematic Review and Meta-Analysis. Ophthalmology, 121, 2081-2090. https://doi.org/10.1016/j.ophtha.2014.05.013

[9] Kumar, A., Basavaraj, M.G., Gupta, S.K., Qamar, I., Ali, A.M., Bajaj, V., et al. (2007) Role of CYP1B1, MYOC, OPTN, and OPTC Genes in Adult-Onset Primary Open-Angle Glaucoma: Predominance of CYP1B1 Mutations in Indian Patients. Molecular Vision, 13, 667-676.

[10] Liu, Y., Akafo, S., Santiago-Turla, C., Cohen, C.S., Larocque-Abramson, K.R., Qin, X., Herndon, L.W., et al. (2008) Optineurin Coding Variants in Ghanaian Patients with Primary Open-Angle Glaucoma. Molecular Vision, 14, 2367-2372.

[11] Fuse, N., Takahashi, K., Akiyama, H., Nakazawa, T., Seimiya, M., et al. (2004) Molecular Genetic Analysis of Optineurin Gene for Primary Open-Angle and Normal Tension Glaucoma in the Japanese Population. Journal of Glaucoma, 13, 299-303. https://doi.org/10.1097/00061198-200408000-00007

[12] Weidberg, H. and Elazar, Z. (2011) TBK1 Mediates Crosstalk between the Innate Immune Response and Autophagy. Science Signaling, 4, pe39.

https://doi.org/10.1126/scisignal.2002355 
[13] Wild, P., Farhan, H., McEwan, D.G., Wagner, S., Rogov, V.V., Brady, N.R., et al. (2011) Phosphorylation of the Autophagy Receptor Optineurin Restricts Salmonella Growth. Science, 333, 228-233. https://doi.org/10.1126/science.1205405

[14] Sudhakar, C., Nagabhushana, A., Jain, N. and Swarup, G. (2009) NF- ${ }_{k} B$ Mediates Tumor Necrosis Factor Alpha-Induced Expression of Optineurin, a Negative Regulator of $\mathrm{NF}_{\mathrm{k}} \mathrm{B}$. PLoS ONE, 4, e5114. https://doi.org/10.1371/journal.pone.0005114

[15] Zhu, G., Wu, C.J., Zhao, Y. and Ashwell, J.D. (2007) Optineurin Negatively Regulates TNF $\alpha$-Induced $\mathrm{NF}_{-\mathrm{k}} \mathrm{B}$ Activation by Competing with NEMO for Ubiquitinated RIP. Current Biology, 17, 1438-1443. https://doi.org/10.1016/j.cub.2007.07.041

[16] Sirohi, K., Chalasani, M.L., et al. (2013) M98K-OPTN Induces Transferrin Receptor degradation and RAB12-Mediated Autophagic Death in Retinal Ganglion Cells. Autophagy, 9, 510-527.https://doi.org/10.4161/auto.23458

[17] Minegishi, Y., Iejima, D., Kobayashi, H., Chi, Z.L., et al. (2013) Enhanced Optineurin E50K-TBK1 Interaction Evokes Protein Insolubility and Initiates Familial Primary Open-Angle Glaucoma. Human Molecular Genetics, 22, 3559-3567. https://doi.org/10.1093/hmg/ddt210

[18] Minegishi, Y., Nakayama, M., Iejima, D., Kawase, K. and Iwata, T. (2016) Significance of Optineurin Mutations in Glaucoma and Other Diseases. Progress in Retinal and Eye Research, 55, 149-181. https://doi.org/10.1016/j.preteyeres.2016.08.002

[19] Chalasani, M.L., Kumari, A., Radha, V. and Swarup, G. (2014) E50K-OPTN-Induced Retinal Cell Death Involves the Rab GTPase-Activating Protein, TBC1D17 Mediated Block in Autophagy. PLoS ONE, 9, e95758.

https://doi.org/10.1371/journal.pone.0095758

[20] Inagaki, S., Kawase, K., Funato, M., Seki, J., Kawase, C., et al. (2018) Effect of Timolol on Optineurin Aggregation in Transformed Induced Pluripotent Stem Cells Derived From Patient with Familial Glaucoma. Investigative Ophthalmology \& Visual Science, 59, 2293-2304. https://doi.org/10.1167/iovs.17-22975

[21] Shim, M.S., Takihara, Y., Kim, K.Y., et al. (2016) Mitochondrial Pathogenic Mechanism and Degradation in Optineurin E50K Mutation-Mediated Retinal Ganglion Cell Degeneration. Scientific Reports, 6, Article No. 33830. https://doi.org/10.1038/srep33830

[22] Takahashi, K., Tanabe, K., Ohnuki, M., Narita, M., et al. (2007) Induction of Pluripotent Stem Cells from Adult Human Fibroblasts by Defined Factors. Cell, 131, 861-872. https://doi.org/10.1016/j.cell.2007.11.019

[23] Kondo, T., Asai, M., Tsukita, K., Kutoku, Y., et al. (2013) Modeling Alzheimer's disease with iPSCs Reveals Stress Phenotypes Associated with Intracellular A $\beta$ and Differential Drug Responsiveness. Cell Stem Cell, 12, 487-496.

https://doi.org/10.1016/j.stem.2013.01.009

[24] Yoshida, M., Kitaoka, S., Egawa, N., Yamane, M., et al. (2015) Modeling the Early Phenotype at the Neuromuscular Junction of Spinal Muscular Atrophy Using Patient-Derived iPSCs. Stem Cell Reports, 4, 561-568.

https://doi.org/10.1016/j.stemcr.2015.02.010

[25] Tucker, B.A., Solivan-Timpe, F., Roos, B.R., Anfinson, K.R., et al. (2014) Duplication of TBK1 Stimulates Autophagy in iPSC-Derived Retinal Cells from a Patient with Normal Tension Glaucoma. Journal of Stem Cell Research \& Therapy, 3, 161. https://doi.org/10.4172/2157-7633.1000161

[26] Xie, B.B., Zhang, X.M., Hashimoto, T., Tien, A.H., Chen, A., Ge, J. and Yang, X.J. (2014) Differentiation of Retinal Ganglion Cells and Photoreceptor Precursors from Mouse Induced Pluripotent Stem Cells Carrying an Atoh7/Math5 Lineage Reporter. 
PLoS ONE, 9, e112175. https://doi.org/10.1371/journal.pone.0112175

[27] Yang, X., Luo, C., et al. (2011) Neurodegenerative and Inflammatory Pathway Components Linked to TNF-alpha/TNFR1 Signaling in the Glaucomatous Human Retina. Investigative Ophthalmology \& Visual Science, 52, 8442-8454. https://doi.org/10.1167/iovs.11-8152

[28] Ojino, K., Shimazawa, M., et al. (2015) Involvement of Endoplasmic Reticulum Stress in Optic Nerve Degeneration after Chronic High Intraocular Pressure in DBA/2J Mice. Journal of Neuroscience Research, 93, 1675-1683. https://doi.org/10.1002/jnr.23630

[29] Shimazawa, M., et al. (2007) Involvement of ER Stress in Retinal Cell Death. Molecular Vision, 13, 578-587.

[30] Lipton, S.A. and Rosenberg, P.A. (1994) Excitatory Amino Acids as a Final Common Pathway for Neurologic Disorders. The New England Journal of Medicine, 330, 613-622. https://doi.org/10.1056/NEJM199403033300907

[31] Harada, T., Harada, C., Nakamura, K., et al. (2007) The Potential Role of Glutamate Transporters in the Pathogenesis of Normal Tension Glaucoma. The Journal of Clinical Investigation, 117, 1763-1770. https://doi.org/10.1172/JCI30178

[32] Kitaoka, Y., Kitaoka, Y., Kwong, J.M., Ross-Cisneros, F.N., et al. (2006) TNF- $\alpha$-Induced Optic Nerve Degeneration and Nuclear Factor ${ }_{\mathrm{k}} \mathrm{B}$ p65. Investigative Ophthalmology \& Visual Science, 47, 1448-1457. https://doi.org/10.1167/iovs.05-0299

[33] Tezel, G., Li, L.Y., Patil, R.V. and Wax, M.B. (2001) TNF- $\alpha$ and TNF- $\alpha$ Receptor-1 in the Retina of Normal and Glaucomatous Eyes. Investigative Ophthalmology \& Visual Science, 42, 1787-1794.

[34] Tezel, G. (2008) TNF- $\alpha$ Signaling in Glaucomatous Neurodegeneration. Progress in Brain Research, 173, 409-421. https://doi.org/10.1016/S0079-6123(08)01128-X

[35] Nakazawa, T., Nakazawa, C., Matsubara, A., et al. (2006) Tumor Necrosis Factor- $\alpha$ Mediates Oligodendrocyte Death and Delayed Retinal Ganglion Cell Loss in a Mouse Model of Glaucoma. The Journal of Neuroscience: The Official Journal of the Society for Neuroscience, 26, 12633-12641. https://doi.org/10.1523/JNEUROSCI.2801-06.2006

[36] Pinazo-Durán, M.D., Zanón-Moreno, V., Gallego-Pinazo, R. and García-Medina, J.J. (2015) Oxidative Stress and Mitochondrial Failure in the Pathogenesis of Glaucoma Neurodegeneration. Progress in Brain Research, 220, 127-153. https://doi.org/10.1016/bs.pbr.2015.06.001

[37] Leruez, S., Marill, A., Bresson, T., de Saint Martin, G., et al. A. (2018) A Metabolomics Profiling of Glaucoma Points to Mitochondrial Dysfunction, Senescence, and Polyamines Deficiency. Biochemistry and Molecular Biology, 59, 4355-4361. https://doi.org/10.1167/iovs.18-24938

[38] Deng, S., Wang, M., Yan, Z., Tian, Z., et al. (2013) Autophagy in Retinal Ganglion Cells in a Rhesus Monkey Chronic Hypertensive Glaucoma Model. PLoS ONE, 8, e77100. https://doi.org/10.1371/journal.pone.0077100

[39] Park, H.Y., Kim, J.H. and Park, C.K. (2012) Activation of Autophagy Induces Retinal Ganglion Cell Death in a Chronic Hypertensive Glaucoma Model. Cell Death \& Disease, 3, e290. https://doi.org/10.1038/cddis.2012.26

[40] Russo, R., Nucci, C., Corasaniti, M.T., Bagetta, G. and Morrone, L.A. (2015) Autophagy Dysregulation and the Fate of Retinal Ganglion Cells in Glaucomatous Optic Neuropathy. Progress in Brain Research, 220, 87-105. https://doi.org/10.1016/bs.pbr.2015.04.009 
[41] Hu, X., Dai, Y. and Sun, X. (2017) Parkin Overexpression Protects Retinal Ganglion Cells against Glutamate Excitotoxicity. Molecular Vision, 23, 447-456.

[42] Chang, Z.-Y., Yeh, M.K., Chiang, C.H., Chen, Y.-H. and Lu, D.-W. (2013) Erythropoietin Protects Adult Retinal Ganglion Cells against NMDA-, Trophic Factor Withdrawal-, and TNF- $\alpha$-Induced Damage. PLOS ONE, 8, e55291. https://doi.org/10.1371/journal.pone.0055291

[43] Kamalden, T.A., Ji, D. and Osborne, N.N. (2012) Rotenone-Induced Death of RGC-5 Cells Is Caspase Independent, Involves the JNK and p38 Pathways and Is Attenuated by Specific Green Tea Flavonoids. Neurochemical Research, 37, 1091-1101. https://doi.org/10.1007/s11064-012-0713-5

[44] Han, M.L., Liu, G.H., Guo, J., Yu, S.J. and Huang, J. (2016) Imipramine Protects Retinal Ganglion Cells from Oxidative Stress through the Tyrosine Kinase Receptor B Signaling Pathway. Neural Regeneration Research, 11, 476-479. https://doi.org/10.4103/1673-5374.179066

[45] Bansal, M., Swarup, G. and Balasubramanian, D. (2015) Functional Analysis of Optineurin and Some of Its Disease-Associated Mutants. IUBMB Life, 67, 120-128. https://doi.org/10.1002/iub.1355

[46] Delhase, M., Kim, S.Y., Lee, H., et al. (2012) TANK-Binding Kinase 1 (TBK1) Controls Cell Survival through PAI-2/SerpinB2 and Transglutaminase 2. Proceedings of the National Academy of Sciences of the United States of America, 109, E177-E186. https://doi.org/10.1073/pnas.1119296109

[47] Ying, H., Shen, X., Park, B. and Yue, B.Y. (2010) Posttranslational Modifications, Localization, and Protein Interactions of Optineurin, the Product of a Glaucoma gene. PLoS ONE, 5, e9168. https://doi.org/10.1371/journal.pone.0009168

[48] Medinas, D.B., Rozas, P., Martinez Traub, F., et al. (2018) Endoplasmic Reticulum Stress Leads to Accumulation of Wild-Type SOD1 Aggregates Associated with Sporadic Amyotrophic Lateral Sclerosis. Proceedings of the National Academy of Sciences of the United States of America, 115, 8209-8214. https://doi.org/10.1073/pnas.1801109115

[49] Korac, J., Schaeffer, V., Kovacevic, I., Clement, A.M., et al. (2013) Dikic, Ubiquitin-Independent Function of Optineurin in Autophagic Clearance of Protein Aggregates. Journal of Cell Science, 126, 580-592. https://doi.org/10.1242/jcs.114926 